Ségolène de Dainville-Barbiche, Devenir curé à Paris. Institutions et carrières ecclésiastiques (1695-1789)

Paris, Presses Universitaires de France, coll. « Le Nœud Gordien », 2005, $550 \mathrm{p}$.

Jean-Pascal Gay

\title{
CpenEdition
}

Journals

Édition électronique

URL : http://journals.openedition.org/assr/15093

DOI : $10.4000 /$ assr. 15093

ISSN : $1777-5825$

Éditeur

Éditions de l'EHESS

Édition imprimée

Date de publication : 1 juin 2008

Pagination : 191-321

ISBN : 978-2-7132-2190-3

ISSN : 0335-5985

Référence électronique

Jean-Pascal Gay, « Ségolène de Dainville-Barbiche, Devenir curé à Paris. Institutions et carrières ecclésiastiques (1695-1789) », Archives de sciences sociales des religions [En ligne], 142 | avril-juin 2008, document 142-19, mis en ligne le 25 novembre 2008, consulté le 21 septembre 2020. URL : http:// journals.openedition.org/assr/15093; DOI : https://doi.org/10.4000/assr.15093

Ce document a été généré automatiquement le 21 septembre 2020.

(c) Archives de sciences sociales des religions 


\section{Ségolène de Dainville-Barbiche, Devenir curé à Paris. Institutions et carrières ecclésiastiques (1695-1789)}

Paris, Presses Universitaires de France, coll. « Le Nœud Gordien », 2005, $550 \mathrm{p}$.

Jean-Pascal Gay

1 L'ouvrage de Ségolène de Dainville-Barbiche, paru en 2005, est certainement un outil de travail très utile pour le chercheur qui s'intéresse à l'histoire du clergé français à l'époque moderne ou plus largement à l'histoire religieuse de la France moderne. Il s'inscrit à l'intersection de deux thématiques de recherche qui ont fait l'objet de contributions importantes à l'historiographie récente du catholicisme moderne: l'étude du personnel des curés - l'Histoire des Curés publié en 2002 sous la direction de Nicole Lemaître sert ici de référence explicite -, et en particulier des curés parisiens étudiés pour le $\mathrm{xVI}^{\mathrm{e}}$ siècle par Vladimir Angelo (Les curés de Paris au XVI ${ }^{e}$ siècle, Paris, Cerf, 2005) d'une part, et d'autre part l'étude des causes internes de l'affaiblissement du catholicisme classique dans le siècle qui précède la révolution, et c'est cette fois l'ouvrage de Pierre Chaunu, Madeleine Foisil et Francoise de Noirfontaine sur Le basculement religieux de Paris au XVIII siècle: Essai d'histoire politique et religieuse (Paris, Fayard, 2002) qui est l'horizon historiographique de l'ouvrage. En raison des enjeux problématiques dans lesquels ce dernier s'inscrit, l'auteure y propose une enquête à la fois plus large et plus restreinte que le titre de l'ouvrage ne le laisse supposer. Bien plus qu'une étude des processus institutionnels ou sociaux d'accession aux cures de la capitale, du devenir curé, il s'agit d'une étude du devenir des curés parisiens au XVIII ${ }^{\mathrm{e}}$ siècle, de l'épiscopat du cardinal de Noailles jusqu'à la Révolution, laquelle, cependant, n'est pas seulement ou pas à proprement parler une histoire sociale du groupe des curés parisiens.

2 L'ouvrage, de fait, insiste sur la nécessité d'un passage par la théologie et le droit de la charge d'âme et du système bénéficial qui l'organise, à la fois parce que les ressorts en demeurent trop peu connus des historiens, mais aussi parce que le droit conditionne les 
stratégies et détermine l'espace dans lequel celles-ci se déploient. Le choix d'une lecture canonique et institutionnelle explique alors, autant qu'il repose sur lui, le choix documentaire original de l'ouvrage. En l'absence de registres d'insinuations, dont les travaux récents de L. Balavoine ont montré l'intérêt pour l'étude détaillée des carrières ecclésiastiques, l'auteure a dû s'appuyer sur les actes notariés et les délibérations des chapitres parisiens.

C'est donc très logiquement que l'ouvrage s'ouvre sur la description des cadres institutionnels de l'Église de Paris: description du cadre géographique des paroisses parisiennes, description de l'organisation hiérarchique du diocèse et de la paroisse. C'est alors une première évolution majeure qui est mise en valeur. Si le XVIII siècle apparait, en partie, comme un âge d'or de la paroisse, en particulier parce qu'il semble marqué par l'activité et l'autorité tant des curés que des fabriques, il est aussi le temps d'une inadéquation de plus en plus criante entre les moyens et les cadres de la pastorale, d'une part, et les besoins d'une population parisienne qui connaît des transformations démographiques majeures notamment en termes de répartition dans l'espace diocésain.

Une fois planté le décor institutionnel des carrières ecclésiastiques, l'auteure décrit l'économie fiduciaire et honorifique qui les sous-tend en examinant dans un premier temps la fiscalité ecclésiastique qui permet d'avoir accès aux revenus des cures, d'en comprendre l'attrait financier mais aussi certains aspects de la circulation des bénéfices, puis la composition des revenus et les charges qui pèsent sur les curés, avant de pouvoir comprendre la logique de l'enrichissement de l'accumulation de l'honneur. L'étude riche et détaillée permet à la fois de saisir l'extrême diversité des revenus issus de l'exercice de la charge curiale, allant de un à soixante, et la manière dont cette diversité détermine des hiérarchies subtiles à l'intérieur des groupes étudiés avec des cures de passage, d'autres comme Saint-Gervais qui sont des cures pauvres mais de fin de carrière et des cures plus recherchées.

5 La troisième partie de l'ouvrage semble s'éloigner un temps de la perspective essentiellement institutionnelle et canonique déployée avec minutie dans les parties précédentes. L'enjeu en demeure cependant essentiel à la logique même du texte qui est d'explorer par le prisme du groupe des curés les raisons du basculement religieux parisien. Reprenant largement la périodisation par épiscopat, proposée dans Le Basculement religieux de Paris au XVIII siècle, l'auteure dans cette partie intitulée «l'hypothèque janséniste » explore la manière dont les curés de Paris ont participé aux vicissitudes de l'histoire religieuse nationale et parisienne et la manière dont ces dernières les ont affectés. L'approche est alors essentiellement événementielle, elle vise cependant à dégager les processus historiques par lesquels les jansénistes, installés dans les cures parisiennes par Noailles, ont été progressivement marginalisés dans le clergé parisien, et comment l'épiscopat a progressivement repris la main dans le diocèse, deux évolutions que le Concordat de 1801 parachève.

C'est ici que cette partie rejoint la perspective essentiellement institutionnelle et canonique adoptée par l'ouvrage. Elle constitue le volant politique d'évolutions institutionnelles que l'auteure peut alors explorer en détail en reconstituant dans une quatrième et une cinquième parties qui semblent le cœur de l'ouvrage, l'évolution des processus d'accession aux cures, ainsi que celle des litiges et des conflits qui les entourent et viennent éclairer, au fond, le statut social des curés parisiens en permettant de dégager à la fois un profil de carrière et les contours sociaux du milieu 
que forment ces curés. L'auteure parvient alors à éclairer des évolutions majeures du système bénéficial gallican et signale, en particulier, qu'entre les modèles concurrents de provisions des cures, par l'épiscopat, par concours ou par cooptation, ce sont finalement les évêques qui parviennent par des stratégies différenciées et grâce à l'appui final de l'autorité consulaire, à imposer leur autorité même si les curés parisiens sont, plus longtemps que d'autres, restés protégés du "despotisme épiscopal ». Elle signale aussi que les curés, au-delà de la diversité de richesse et de revenus qui est réelle, sont au $\mathrm{XVIII}^{\mathrm{e}}$ conformes à l'idéal tridentin, même si leur formation évolue pour devenir plus juridique, de même d'ailleurs que leur pastorale se transforme. Le moment charnière de la transformation de l'épiscopat parisien serait alors le xvII ${ }^{\mathrm{e}}$ siècle sur lequel le pendant du travail fait ici par Ségolène de Dainville-Barbiche et, pour le $\mathrm{XVI}^{\mathrm{e}}$ siècle, par Vladimir Angelo, demeure à faire.

On le voit, cet ouvrage est riche d'une grande masse d'informations, et si une grande part provient de travaux déjà publiés par l'auteure, leur regroupement dans un seul ouvrage les rend d'autant plus utiles, qu'ils sont complétés par une liste des paroisses et une prosopographie des curés parisiens qui seront très utiles au chercheur en histoire religieuse $\mathrm{du} \mathrm{XVIII}^{\mathrm{e}}$ siècle. Cette utilité compense très largement les défauts que l'on pourrait trouver à ce texte et notamment à son approche parfois un peu transparente du droit canon. La première partie réduit ainsi souvent par l'exemple la distance qui peut exister du droit au fait, sans poser la question des mobilisations et des usages du droit dans la construction des stratégies que le reste du texte décrit si finement. De même, la longue histoire des conflits religieux $d u x_{\text {xvIII }}{ }^{\mathrm{e}}$ siècle français et parisien pourrait paraître un peu superfétatoire, dans la mesure où elle rapporte des épisodes dans l'ensemble bien connus sans vraiment dégager une participation spécifique des curés aux événements et surtout sans revenir véritablement sur l'existence du groupe tant comme groupe social que comme corps réel ou revendiqué. On pourrait encore reprocher à cette partie une définition finalement hésitante du jansénisme balançant entre une définition restrictive en terme idéologique - la réduction du jansénisme au figurisme, que l'ouvrage de Catherine Maire, De la cause de Dieu à la cause de la Nation (Paris, Gallimard, 1998), ne nous semble pas véritablement autoriser - et une définition large en terme de milieu. Là encore, on soulignera l'utilité de joindre cette information au reste de l'étude et la manière dont elle prépare la dernière partie, dans un ouvrage qui est un texte de synthèse. Ici le texte signale surtout des points obscurs dans notre connaissance du monde religieux du XVIII ${ }^{e}$ siècle français, en particulier la réalité et la nature des réseaux jansénistes parisiens que la publication des travaux de Nicolas LyonCaen devraient venir éclairer, de même que la nécessité d'une véritable histoire sociale des franges supérieures du clergé parisien qui intègre des sources plus vastes, comme les actes notariés concernant non seulement les clercs mais encore leurs familles, ce qui permettrait certainement d'approfondir les acquis de la prosopographie offerte ici à la communauté historienne. 